\title{
Treatment of type II endoleaks associated with left subclavian artery coverage during thoracic aortic stent grafting
}

Mark D. Peterson, MD, PhD, Grayson H. Wheatley, III, MD, Jacques Kpodonu, MD, James P. Williams, BSc, Venkatesh G. Ramaiah, MD, Julio A. Rodriguez-Lopez, MD, and Edward B. Diethrich, MD

Objective: Increasing experience with thoracic aortic stent grafts has led to a more aggressive approach to thoracic aortic pathologies in the distal aortic arch and proximal descending thoracic aorta. To increase the length of the proximal landing zone, it is sometimes necessary to cover the left subclavian artery with the thoracic stentgraft, introducing the risk of retrograde filling of the excluded aorta from the left subclavian artery. It is currently unclear how best to manage these patients to prevent persistent risk of aneurysm expansion or rupture. We report our experience with a minimally invasive endovascular repair of the covered left subclavian artery.

Methods: We reviewed prospectively gathered data on all investigational device exemption-approved patients undergoing thoracic aortic stent grafting at the Arizona Heart Institute from 2000 to 2006 ( $n=289$ patients). Patients had surveillance with a contrast-enhanced computed tomography scan on the first postoperative day and during follow-up at 1,6 , and 12 months.

Results: A total of 289 patients received thoracic stent grafts during the study: Medtronic Talent (Medtronic, Minneapolis, Minn) $(n=25)$ or Gore TAG (WL Gore \& Associates Inc, Flagstaff, Ariz) $(n=261)$. The left subclavian artery was covered in $23 \%$ of patients $(n=66)$, of whom $17 \%$ had preoperative carotid-subclavian bypass $(n=11 / 66)$. Among patients with left subclavian artery coverage, the 30 -day mortality was $6.1 \%(n=4)$, procedure-related strokes developed in 3 patients $(\mathrm{n}=3,4.6 \%)$, and the incidence of left arm claudication was $7.6 \%(\mathrm{n}=5)$, necessitating postoperative carotid-subclavian bypass in 2 patients. Twelve patients $(18 \%)$ had a type I $(n=6)$ or II $(n=7)$ endoleak. Coverage of the left subclavian artery accounted for $71 \%$ of the type II endoleaks $(n=5)$, whereas patent intercostals accounted for the rest $(n=2)$. Type II endoleaks associated with left subclavian artery coverage were successfully treated by retrograde coil embolization from the left brachial artery $(n=3)$ or left subclavian artery ligation $(n=1)$.

Conclusion: Coverage of the left subclavian artery during thoracic aortic stent grafting is associated with a low incidence of arm complications and type II endoleaks. All type II endoleaks were successfully treated by retrograde coil embolization or ligation of the left subclavian artery. Successful treatment of endoleaks may reduce the risk of aneurysm expansion or rupture.

In 1994, Dake and colleagues ${ }^{1}$ published a landmark article demonstrating the safe and effective treatment of thoracic aortic aneurysms with endovascular stent-grafts. During the last decade, endovascular techniques have been refined and stent grafts have become commercially available, fueling an explosion of centers that offer endovascular stent grafting to treat a wide range of thoracic aortic pathologies. Although stent grafts were originally designed to treat aneurysms of the descending thoracic aorta, the desire to avoid the morbidity associated with traditional open repair has broadened both the spectrum of thoracic diseases treated

From the Division of Cardiovascular Surgery, Arizona Heart Institute, Phoenix, Ariz. Grayson Wheatley reports consulting fees from Gore, Boston Scientific and Medtronic, and lecture fees from Medtronic. Julio Rodriguez-Lopez reports lecture fees from Gore and Endologix and equity ownership in Endologix and Medtronic.

Received for publication June 7, 2007; revisions received March 27, 2008; accepted for publication May 4, 2008.

Address for reprints: Grayson H. Wheatley, III, MD, Division of Cardiovascular Surgery, Arizona Heart Institute, 2632 North 20th Street, Phoenix, AZ 85006 (E-mail: gwheatley@azheart.com).

J Thorac Cardiovasc Surg 2008;136:1193-9

$0022-5223 / \$ 34.00$

Copyright (C) 2008 by The American Association for Thoracic Surgery

doi:10.1016/j.jtcvs.2008.05.036 and the segments of the proximal and distal aorta deemed suitable for stent grafting.

Pathology adjacent to the left subclavian artery (LSA) may necessitate stent graft coverage of the LSA origin to adequately seal and fix the device at the proximal landing zone. No consensus exists in the literature regarding whether to simply cover the LSA or to revascularize the LSA before stent graft deployment. Several studies have concluded that the risks associated with simply covering the left subclavian are low and reserve subclavian artery bypass only if symptoms develop postoperatively in patients, such as left arm claudication or vertebrobasilar insufficiency. ${ }^{2-10} \mathrm{Con}$ versely, other centers report frequent complications related to overstenting of the left subclavian and thus routinely revascularize the LSA, with few exceptions. ${ }^{11-13}$

The sequelae of covering the LSA potentially include an increased risk of left upper extremity ischemia, vertebrobasilar insufficiency, stroke, and paraplegia. Retrograde filling of the excluded aorta from a patent subclavian artery may also predispose patients to a higher risk of type II endoleaks. The purpose of this study is to determine the sequelae associated with covering the LSA during thoracic aortic stent 


\section{Abbreviations and Acronyms \\ $\mathrm{CT}=$ computed tomography \\ LSA $=$ left subclavian artery}

grafting in a large series of patients, with particular emphasis on the incidence of type II endoleaks related to a patent LSA. We also report our experience with endovascular repair of type II endoleaks associated with a covered LSA.

\section{MATERIALS AND METHODS}

We reviewed prospectively collected data on all patients receiving either Gore TAG (WL Gore \& Associates Inc, Flagstaff, Ariz) or Medtronic Talent (Medtronic, Minneapolis, Minn) thoracic endoprostheses at the Arizona Heart Institute between 2000 and 2006. After institutional ethics review board approval and informed consent were obtained, patients were prospectively enrolled in a single-center investigational device protocol for either the TAG or the Talent endoprosthesis. The study inclusion and exclusion criteria, and the device characteristics have been described. ${ }^{14}$ Similar inclusion criteria applied to patients receiving the Talent endoluminal graft, except that a proximal and distal aortic neck length of at least $10 \mathrm{~mm}$ and a diameter between 18 and $42 \mathrm{~mm}$ were considered acceptable.

We compared patients who received endoluminal grafts to the distal aortic arch and the descending thoracic aorta (LSA covered, $n=66$ ), necessitating coverage of the LSA, with patients who received endoluminal grafting isolated to the descending thoracic aorta (conventional, $\mathrm{n}=223$ ). We excluded patients who underwent concomitant proximal aortic arch endoluminal grafting and great artery transposition, and patients treated with combined thoracic-infraceliac abdominal aortic endoluminal grafting and abdominal visceral artery transposition.

\section{Perioperative Management}

All patients had preoperative contrast-enhanced computed tomography (CT) and intraoperative aortography. In addition to aortography, we routinely examined the aorta from the ascending to the mid-abdominal aorta with intravascular ultrasound (Volcano, Rancho Cordova, Calif) to confirm preoperative $\mathrm{CT}$ measurements of the aortic diameter at the proximal and distal landing zones. Intravascular ultrasound was particularly important for identifying the true and false lumens when treating type B dissections. We also screened most patients with duplex ultrasound to assess the patency of the carotid and vertebral arteries. The presence of an atretic or stenotic right vertebral artery is a potential risk factor for posterior circulation strokes; therefore, we considered this a contraindication to unprotected LSA overstenting. Patients treated on an urgent basis had intraoperative arch aortograms to delineate the patency of the proximal vertebral arteries and to identify potential anomalous vertebral artery origins (ie, arch takeoff).

All procedures were performed by a cardiovascular or vascular surgeon in a hybrid operating room equipped with a fixed, ceiling-mounted imaging system. The details of our intraoperative management have been described. ${ }^{14}$ Briefly, arterial access was obtained by exposing the common femoral artery via a small oblique incision 2 to $3 \mathrm{~cm}$ above the groin crease. If the common femoral or external iliac artery diameter was judged insufficient to permit sheath insertion as determined by preoperative imaging, a 10-mm Dacron graft was anastomosed directly to the common iliac or distal abdominal aorta. After standard aortography and intravascular ultrasound examinations were completed, proximal and distal landing zones were marked, the systolic blood pressure decreased to less than $100 \mathrm{~mm}$ $\mathrm{Hg}$, and the endoprosthesis was deployed over a double-curved, stiff Lunderquist wire (LES3, Cook, Bloomington, Ind). The decision to cover the LSA was based on the diameter of the proximal thoracic aorta, the length of normal aorta beyond the LSA origin, and the inner radius of the aortic arch. If necessary to obtain adequate proximal fixation and seal, while minimizing bird's beaking, the LSA was covered. Early in our series, a left carotid to subclavian bypass was performed before planned coverage of the LSA; however, with increasing experience we bypassed the LSA post-endoluminal grafting only in patients with symptoms of left upper extremity ischemia or vertebrobasilar insufficiency. We considered a patent internal thoracic artery bypass graft and a functioning arteriovenous fistula in the left upper extremity as absolute contraindications to LSA coverage.

Cerebrospinal fluid drains were not routinely used in either group but were placed selectively in patients considered at high risk for paraplegia, such as previous abdominal aortic aneurysm repair. Our postoperative protocol mandated strict blood pressure control to maintain a systolic blood pressure greater than $140 \mathrm{~mm} \mathrm{Hg}$. If paraplegia or paraparesis developed postoperatively, a spinal drain was placed and a high-dose dexamethasone protocol was started.

\section{Follow-up and Endoleak Management}

Per the study protocols, patients had postoperative plain radiographs (4 views) and noncontrast and contrast-enhanced CT scans at 1, 6, and 12 months, and then annually. If an endoleak was identified at 1 month, then a repeat CT scan was performed at 3 months. Endoleaks were classified according to standard nomenclature. ${ }^{15}$ Type II endoleaks were further subdivided according to the causative branch vessel: LSA or intercostal. Persistent type II endoleaks emanating from retrograde flow from the LSA were confirmed by angiography performed percutaneously via a $6 \mathrm{~F}$ sheath placed in the left brachial artery. These endoleaks were treated by depositing multiple platinum coils at the origin of the LSA, adjacent to the stent graft.

\section{Statistical Analysis}

Statistical analysis was performed with SAS software (SAS version 8.1, SAS Institute, Cary, NC). Continuous variables are expressed as mean \pm standard deviation, and categoric variables are expressed as percentages throughout the article. Comparisons of continuous variables between groups were performed with unpaired Student $t$ tests. Categoric variables were analyzed with chi-square or Fisher's exact tests. Backward stepwise logistic regression identified independent predictors of death or paraplegia. Survival between groups was compared by the Kaplan-Meier method.

\section{RESULTS}

The 2 groups of patients were comparable for all preoperative characteristics with the exception that the LSA covered group had a higher proportion of men and patients with a history of replacement of the ascending aorta (Table 1). Early in our series, we performed left carotid-subclavian bypass $(\mathrm{n}=$ 9/11) or LSA transposition $(n=2 / 11)$ before planned coverage of the LSA, resulting in a greater proportion of these patients in the LSA covered group: Eight operations were performed prophylactically, and 3 operations were performed because of a specific contraindication to unprotected LSA coverage (Table 1). The conventional group trended toward a higher prevalence of patients with previous abdominal aortic aneurysm repair and peripheral vascular disease (Table 1).

The prevalence of thoracic aortic pathology varied between the 2 groups (Table $2, P<.001$ ). Acute type B dissections and pseudoaneurysms were more prevalent in patients 
TABLE 1. Preoperative characteristics of patients treated with thoracic endoluminal grafts: Left subclavian artery covered versus isolated descending thoracic aorta (conventional)

\begin{tabular}{|c|c|c|c|}
\hline Variable & $\begin{array}{l}\text { LSA covered } \\
\quad(n=66) \\
\end{array}$ & $\begin{array}{l}\text { Conventional } \\
(\mathrm{n}=\mathbf{2 2 3})\end{array}$ & $P$ value \\
\hline Age (y) & $68 \pm 13$ & $69 \pm 12$ & .3 \\
\hline Male sex & $52(79 \%)$ & $122(55 \%)$ & .0004 \\
\hline Hypertension & $53(80 \%)$ & $165(74 \%)$ & .3 \\
\hline Tobacco use & $47(71 \%)$ & $162(73 \%)$ & .8 \\
\hline $\mathrm{DM}$ & $4(6.1 \%)$ & $18(8.1 \%)$ & 6 \\
\hline CAD & $23(32 \%)$ & $81(35 \%)$ & 6 \\
\hline Preoperative MI & $9(14 \%)$ & $23(10 \%)$ & .4 \\
\hline Atrial fibrillation & $8(12 \%)$ & $15(6.7 \%)$ & .15 \\
\hline CHF & $5(7.6 \%)$ & $21(9.4 \%)$ & .6 \\
\hline PVD & $3(4.6 \%)$ & $27(12 \%)$ & .08 \\
\hline Renal failure & $6(9.1 \%)$ & $23(10 \%)$ & .8 \\
\hline Renal insufficiency & $19(29 \%)$ & $55(25 \%)$ & .5 \\
\hline COPD & $13(20 \%)$ & $51(23 \%)$ & .6 \\
\hline Preoperative CVA & $5(7.6 \%)$ & $18(8.1 \%)$ & .9 \\
\hline Cancer history & $7(11 \%)$ & $20(9.0 \%)$ & .7 \\
\hline \multicolumn{4}{|l|}{ Previous procedure } \\
\hline CABG & $7(11 \%)$ & $20(9.0 \%)$ & .7 \\
\hline AAA repair & $6(9.1 \%)$ & $40(18 \%)$ & .08 \\
\hline TAA repair & $4(6.1 \%)$ & $10(4.5 \%)$ & .6 \\
\hline RAA & $7(11 \%)$ & $7(3.1 \%)$ & .02 \\
\hline $\begin{array}{c}\text { Preoperative carotid } \\
\text { to LSA bypass }\end{array}$ & $11(17 \%)$ & $2(0.9 \%)$ & $<.0001$ \\
\hline
\end{tabular}

$D M$, Diabetes mellitus; $C A D$, coronary artery disease; $M I$, myocardial infarction; $C H F$, congestive heart failure; $P V D$, peripheral vascular disease; $C O P D$, chronic obstructive pulmonary disease; $C V A$, cerebrovascular accident; $C A B G$, coronary artery bypass grafting; $A A A$, aortic abdominal aneurysm; $T A A$, thoracic aortic aneurysm; $R A A$, replacement ascending aorta; $L S A$, left subclavian artery.

requiring coverage of the LSA, whereas aneurysms, including contained ruptures, and penetrating atherosclerotic ulcers were more common in patients requiring stent grafts isolated to the descending thoracic aorta (Table 2).

TABLE 2. Etiology of thoracic aortic disease: Left subclavian artery covered versus isolated descending thoracic aortic (conventional) stenting

\begin{tabular}{lcc}
\hline \multicolumn{1}{c}{ Etiology } & $\begin{array}{c}\text { LSA covered } \\
(\mathbf{n}=\mathbf{6 6})\end{array}$ & $\begin{array}{c}\text { Conventional } \\
(\mathbf{n = 2 2 3})\end{array}$ \\
\hline Aneurysm & $20(30 \%)$ & $97(44 \%)$ \\
Type B dissection & & \\
$\quad$ Acute & $19(29 \%)$ & $26(12 \%)$ \\
$\quad$ Chronic & $10(15 \%)$ & $33(15 \%)$ \\
Penetrating ulcer & $2(3.0 \%)$ & $28(13 \%)$ \\
Contained rupture & $1(1.5 \%)$ & $15(6.7 \%)$ \\
Pseudoaneurysm & $8(12 \%)$ & $8(3.6 \%)$ \\
Traumatic transection & $2(3.0 \%)$ & $8(3.6 \%)$ \\
Aortobronchial fistula & $2(3.0 \%)$ & $5(2.2 \%)$ \\
Atheroembolic aorta & 0 & $2(0.9 \%)$ \\
Coarctation repair & 0 & $1(0.5 \%)$ \\
Endoleak repair & $2(3.0 \%)$ & 0 \\
\hline
\end{tabular}

LSA, Left subclavian artery.
TABLE 3. Procedural characteristics during thoracic endoluminal grafting: Left subclavian artery covered versus isolated descending thoracic aortic (conventional) stenting

\begin{tabular}{lccc}
\hline \multicolumn{1}{c}{ Variable } & $\begin{array}{c}\text { LSA covered } \\
(\mathbf{n}=\mathbf{6 6})\end{array}$ & $\begin{array}{c}\text { Conventional } \\
(\mathbf{n = 2 2 3})\end{array}$ & $\boldsymbol{P}$ Value \\
\hline Estimated blood loss (mL) & $378 \pm 301$ & $403 \pm 474$ & .7 \\
Contrast (mL) & $379 \pm 171$ & $323 \pm 172$ & .02 \\
No. of grafts/patient & $1.5 \pm 0.75$ & $1.5 \pm 0.98$ & .9 \\
$\begin{array}{l}\text { Type of device } \\
\quad \text { Gore TAG }\end{array}$ & $62(94 \%)$ & $199(89 \%)$ & .6 \\
$\quad$ WL Gore \& Associates & & & \\
$\quad$ Inc, Flagstaff, Ariz) & & & \\
$\quad \begin{array}{l}\text { Medtronic Talent (Medtronic, } \\
\quad \text { Minneapolis, Minn) }\end{array}$ & $4(6 \%)$ & $21(9.4 \%)$ & \\
$\quad$ Both & 0 & $3(1.4 \%)$ & \\
Retroperitoneal conduit & $4(6.1 \%)$ & $28(13 \%)$ & .14 \\
\hline LSA, Left subclavian artery. & \multicolumn{3}{c}{}
\end{tabular}

Table 3 summarizes the procedural characteristics for both groups. The majority of patients in both groups were treated with a Gore TAG endoprosthesis, with a few patients receiving Medtronic Talent devices. The intraoperative variables were similar for both groups; however, careful positioning of a stent graft distal to the left common carotid artery during planned coverage of the LSA required a greater volume of contrast compared with isolated descending thoracic aortic stenting (Table 3 ).

The 2 groups were similar for all postoperative outcome variables, except patients who had the LSA covered during stent grafting had a higher incidence of left upper extremity claudication (Table $4,7.6 \%$ vs $0.5 \%$ for LSA covered vs conventional, respectively, $P=.003$ ) Symptoms related to subclavian artery coverage were generally mild and consisted of left upper extremity fatigue with exercise, coolness, and episodic paresthesias. Two patients $(2 / 66,3 \%)$ experienced symptoms severe enough to warrant postoperative subclavian revascularization: One patient had severe

TABLE 4. Postoperative outcomes after thoracic endoluminal grafting: Left subclavian artery covered versus isolated descending thoracic aortic (conventional) stenting

\begin{tabular}{lcrc}
\hline \multicolumn{1}{c}{ Outcome } & $\begin{array}{c}\text { LSA covered } \\
(\mathbf{n}=\mathbf{6 6})\end{array}$ & $\begin{array}{c}\text { Conventional } \\
(\mathbf{n}=\mathbf{2 2 3})\end{array}$ & $\boldsymbol{P}$ value \\
\hline Perioperative MI & $3(4.6 \%)$ & $5(2.2 \%)$ & .3 \\
Respiratory failure & 0 & $5(2.2 \%)$ & .6 \\
Renal failure & $3(4.6 \%)$ & $12(5.4 \%)$ & 1.0 \\
Stroke/TIA & $3(4.6 \%)$ & $8(3.6 \%)$ & .7 \\
Paraplegia/paraparesis & $2(3.0 \%)$ & $10(4.5 \%)$ & 1.0 \\
Access complications & & & .2 \\
$\quad$ Iliac rupture & 0 & $3(1.4 \%)$ & \\
$\quad$ Iliac stent & 0 & $10(4.5 \%)$ & \\
Left upper extremity & $5(7.6 \%)$ & $1(0.5 \%)$ & .003 \\
$\quad$ claudication & & & \\
Length of stay & $4.8 \pm 4.9$ & $5.0 \pm 4.9$ & .8 \\
Mortality, 30 d & $4(6.1 \%)$ & $10(4.5 \%)$ & .5 \\
\hline
\end{tabular}

$M I$, Myocardial infarction; TIA, transient ischemic attack. 
postoperative numbness and paresthesias that may have been related to a synchronous left brachial thrombus; nevertheless, the patient underwent simultaneous brachial embolectomy and LSA transposition. One patient experienced left arm claudication in conjunction with intermittent dizziness necessitating carotid-subclavian bypass 3 weeks after the initial procedure.

The incidence of neurologic complications was similar in both groups (Table 4). There were no cases of paraplegia in the group with the LSA covered; however, 2 patients experienced paraparesis: One patient had mild bilateral lower extremity weakness after placement of 2 stent grafts for a ruptured type $\mathrm{B}$ dissection, and 1 patient experienced isolated, mild right lower extremity weakness that completely resolved by 6 months. Three patients $(4.6 \%)$ in the LSA covered group experienced perioperative strokes: 1 left temporoparietal stroke, 1 parieto-occipital stroke, and 1 undetermined territory (the patient died of a new stroke after transfer to an outside facility).

Twelve patients $(18 \%)$ who had the LSA covered developed a type I $(n=6 / 66)$ or II $(n=7 / 66)$ endoleak diagnosed immediately after stent grafting or during follow-up (1 patient had both type I and II endoleaks). Table 5 summarizes the type II endoleaks according to the branch vessel supplying the endoleak. Retrograde flow from a covered LSA accounted for $71 \%$ of the type II endoleaks $(n=5)$, whereas patent intercostals accounted for the rest $(n=2)$. Type II endoleaks associated with left subclavian coverage were successfully treated by either retrograde coil embolization from the left brachial artery $(n=3$, Figure 1$)$ or left subclavian ligation in conjunction with carotid-subclavian bypass $(n=1)$. One patient had a small type II endoleak from a patent LSA diagnosed at 1 month postoperatively; however, the 6-month CT scan demonstrated complete resolution of the endoleak. Two patients with type II endoleaks emanating from patent intercostals were managed conservatively: The endoleak resolved in 1 patient by 6 months, and the other patient was lost to follow-up.

The 30-day mortality was similar between the 2 groups (Table $4,6.1 \%$ vs $4.5 \%$ for LSA covered vs conventional group, respectively, $P=.5$ ). The 5-year mortality was equivalent between groups (Figure 2, $68.3 \%$ vs $69.4 \%$ for LSA covered vs conventional group, respectively, $P=.5$ ).

\section{DISCUSSION}

In this study, we reviewed our large series of patients who had the LSA covered during endovascular stent graft repair for thoracic aortic pathology and compared the results with those of patients undergoing stent grafting isolated to the descending thoracic aorta. We demonstrate that overstenting of the LSA is associated with a relatively low incidence of left upper extremity complications, a low stroke and paraplegia rate comparable to patients who did not have left subclavian overstenting, and a low incidence of type II endoleaks.

To adequately fix thoracic stent grafts in the proximal landing zone, high-volume thoracic endografting centers cover the LSA in $12 \%$ to $34 \%$ of all thoracic cases. $^{2,4,6,14,16-18}$ We covered the LSA in $23 \%$ of patients ( $n=66 / 289$ ) who underwent thoracic endografting for a wide range of thoracic aortic pathologies, confirming that LSA coverage is necessary in a large number of patients. Despite the frequent need to cover the LSA during thoracic stent grafting, no uniform consensus exists regarding whether to selectively or routinely revascularize the LSA.

Early in our experience, we electively revascularized the first 8 patients $(12 \%)$ scheduled for planned coverage of the LSA, but our management evolved over the study period to revascularize patients only if they had a specific contraindication to unprotected overstenting (3 patients), namely, a patent left internal thoracic to left anterior artery descending artery bypass, a functioning left upper extremity arteriovenous fistula, or stenosis of the vertebral arteries. Thus, the majority of patients $(83 \%, \mathrm{n}=55 / 66)$ who had LSA overstenting did not have preoperative revascularization, yet only 5 patients $(9 \%, \mathrm{n}=5 / 55)$ developed left arm claudication and only 2 patients required postoperative LSA revascularization to relieve left arm claudication or paresthesias. No patient developed critical limb ischemia or rest pain. The extensive collateral blood supply to the left subclavian and axillary arteries may explain the low incidence of acute

TABLE 5. Treatment of type II endoleaks associated with coverage of the left subclavian artery $(n=66)$

\begin{tabular}{|c|c|c|c|c|}
\hline Type II endoleak & Patient & Time from procedure & Reintervention & Follow-up \\
\hline \multicolumn{5}{|c|}{ Retrograde from LSA $(n=5 / 66)$} \\
\hline & 1 & POD 2 & Coiled from L brachial & Sealed \\
\hline & 2 & $1 \mathrm{y}$ & $\begin{array}{l}\text { Ligation LSA and L carotid-subclavian } \\
\text { bypass }\end{array}$ & Sealed \\
\hline & 3 & OR & Coiled from L brachial & Sealed \\
\hline & 4 & $1 \mathrm{mo}$ & No & Sealed \\
\hline & 5 & $6 \mathrm{mo}$ & Coiled from L brachial & Sealed \\
\hline \multicolumn{5}{|l|}{ Intercostal artery $(n=2 / 66)$} \\
\hline & 5 & $1 \mathrm{mo}$ & No & Lost to follow-up \\
\hline & 6 & $1 \mathrm{mo}$ & No & Sealed \\
\hline
\end{tabular}

LSA, Left subclavian artery; $P O D$, postoperative day; $L$, left; $O R$, operating room. 

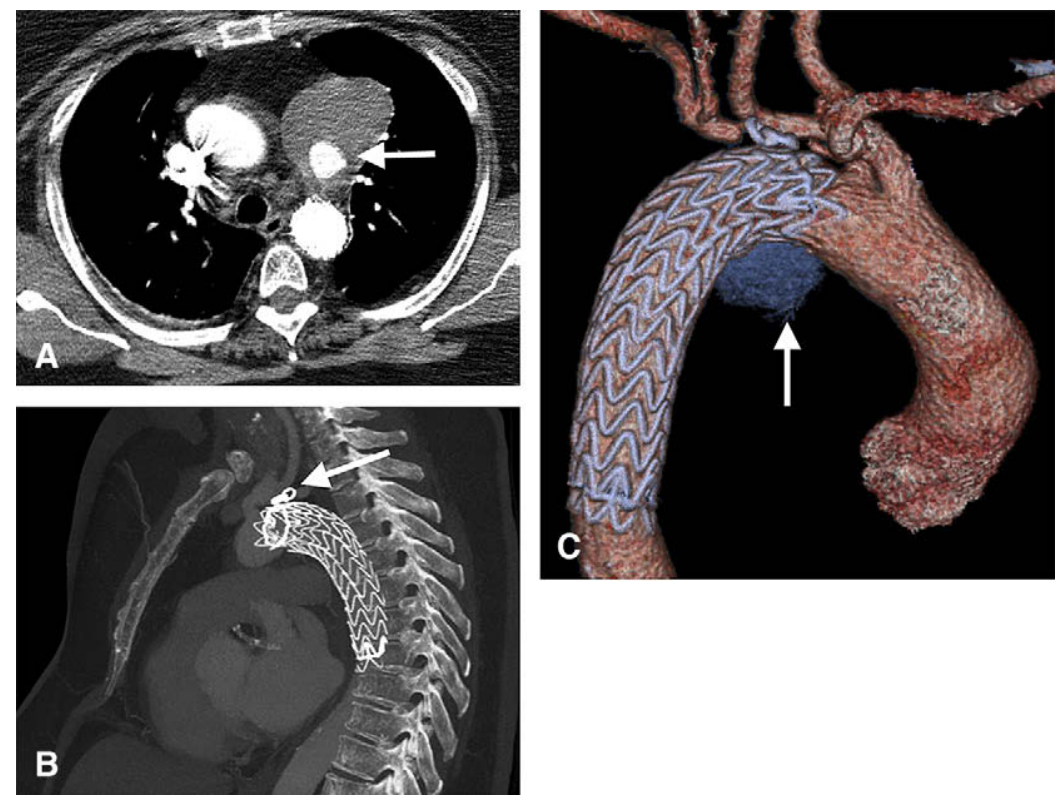

FIGURE 1. Endovascular repair of a type II endoleak emanating from a patent LSA. A, Post-thoracic endograft CT demonstrating a large type II endoleak (arrow). Sagittal (B) and 3-dimensional 64-slice CT reconstructions (C) after multiple platinum coils (arrow) were placed at the origin of the LSA, adjacent to the endograft, with seal of the endoleak (thrombus depicted by arrow).

ischemia observed after coverage of the left subclavian origin: most studies report a $0 \%$ incidence of acute left upper extremity ischemia; $;^{3-8,10,17}$ however, a few cases of critical ischemia ${ }^{13}$ or rest pain ${ }^{2}$ have been described. The reported incidence of left upper extremity symptoms, such as claudication, weakness, coolness, or paresthesias, attributable to LSA coverage, is more variable and ranges from $0 \%$ to $35 \% .^{2-7,10}$

Coverage of the LSA may also increase the risk of posterior circulation strokes, particularly if the right vertebral artery is absent or stenotic. In the present series, the incidence of stroke was comparable between the 2 groups ( $4.6 \%$ vs

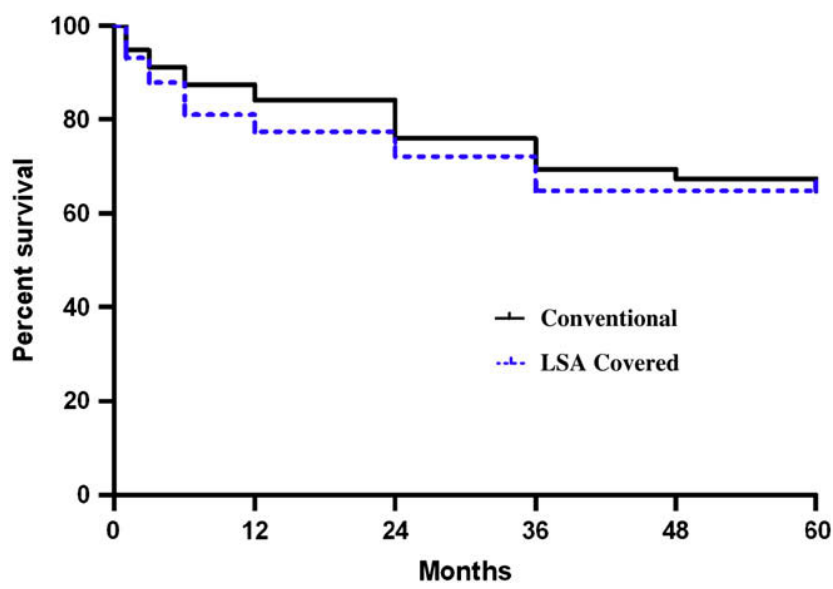

FIGURE 2. Long-term survival for the LSA covered versus the conventional group by the Kaplan-Meier method. LSA, Left subclavian artery.
$3.6 \%$ for LSA covered and conventional, respectively). Only 1 patient in whom the LSA was covered had a confirmed posterior circulation stroke, suggesting that the majority of strokes in both groups were atheroembolic, induced by manipulating guidewires, catheters, and devices in the transverse arch. The incidence of stroke reported by institutions with considerable experience with left subclavian overstenting ranges from $0 \%{ }^{4,17}$ to $1.6 \%{ }^{6}$ to as high as $10.7 \% ;^{2}$ the majority of the strokes observed in these studies were also attributed to atheroemboli based on the pattern and distribution of lesions observed on postoperative head CT scans. ${ }^{2,6}$ A recent study of 153 patients who underwent thoracic stent grafting identified peripheral vascular embolization as a predictor of stroke, further supporting the concept that atheroemboli is the major source of strokes during stent grafting. ${ }^{19}$ The LSA was covered in 39 patients $(25 \%)$ in this study and was not identified as a predictor of stroke.

In contrast, several other studies suggest an association between left subclavian overstenting and posterior circulation strokes. ${ }^{7,12,16}$ Peterson and colleagues ${ }^{12}$ noted 4 postoperative strokes in 8 patients who had left subclavian overstenting without previous revascularization; 1 patient had a left middle cerebral territory stroke, and 3 patients had posterior circulation strokes. Although 1 of the patients with a posterior circulation stroke also had small diffuse strokes in both anterior cerebral distributions, suggestive of atheroembolic strokes, 2 of these patients had left-sided posterior strokes and review of the preoperative imaging revealed that the right vertebral was absent in both cases. 
Preoperative imaging to establish the completeness of the circle of Willis does not necessarily predict the patients who are at risk for developing posterior circulation strokes. Song and colleagues ${ }^{7}$ observed 3 of 42 posterior circulation strokes after thoracic endografting (2/11 in patients with left subclavian overstenting), despite a normal intracerebral circulation as defined by preintervention magnetic resonance angiography.

Although our data confirm that the incidence of posterior circulation strokes is likely low, a careful and thorough preoperative evaluation is warranted to minimize the stroke risk and guide the decision to revascularize the LSA before overstenting. We routinely evaluate the carotid and vertebral arteries before planned LSA coverage with duplex ultrasound. In emergency cases, such as traumatic disruption or contained rupture, we attempt to visualize the vertebral arteries with intraoperative angiography. A hemodynamically significant stenosis or an absent right vertebral artery would prompt preintervention revascularization of the LSA. Early in our series, we did not routinely assess the anatomy of the intracerebral circulation; however, we have started evaluating the cerebrovascular circulation with reconstructed 64-slice CT scans (Figure 3). Although the relationship between an incomplete circle of Willis and the risk of posterior circulation stroke during LSA overstenting is unclear at present, a cautious approach would be to revascularize the LSA before overstenting if an incomplete circle of Willis was documented on preoperative imaging.

Spinal cord ischemia and paraplegia are complications after thoracic stent-graft repair. Most large series report an incidence of paraplegia/paraparesis between $2 \%$ and $4 \%$ (range $0 \%-6.7 \%)^{6,14,16,18-23}$ Coverage of the hypogastric arteries ${ }^{19}$ previous or concomitant abdominal aortic aneurysm repair, ${ }^{24}$ or extensive coverage of the aorta ${ }^{25}$ may compromise collateral blood flow to the spinal cord and have all been cited as risk factors for spinal cord ischemia. The LSA also supplies collateral blood flow to the spinal cord via the vertebral and anterior spinal arteries, yet coverage of the origin of the LSA does not seem to increase the risk of paraplegia/paraparesis. ${ }^{2,5-7,19,23}$ In the present series, the risk of spinal cord ischemia was similar in the 2 groups (3\% vs $4.5 \%$ for LSA covered and conventional, respectively), despite a $9.1 \%$ and an $18 \%$ prevalence of previous abdominal aortic aneurysm repair in the LSA covered and the conventional groups, respectively.

Covering the origin of the LSA without previous ligation or transposition has the added potential to fill the excluded aorta retrogradely, resulting in a type II endoleak. The natural history of type II endoleaks after thoracic endografting was initially considered benign; however, several recent reports indicate continued aneurysm sac expansion in the presence of a type II endoleak. ${ }^{26,27}$ We observed type II endoleaks secondary to retrograde filling via the LSA in $7.6 \%$ of patients $(5 / 66)$. The endoleak resolved spontaneously in 1

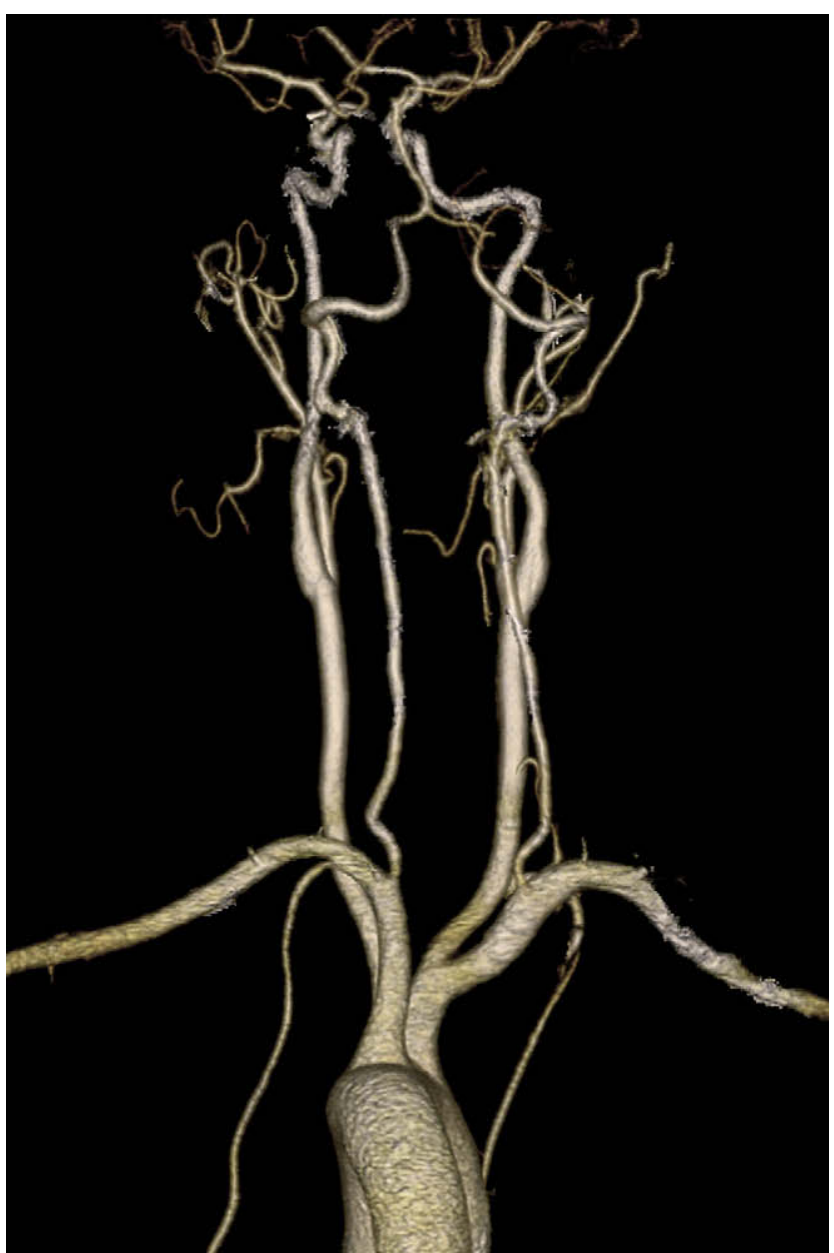

FIGURE 3. Preoperative assessment of normal cerebrovascular anatomy in a patient scheduled for thoracic endografting with planned LSA coverage (3-dimensional reconstructions based on a 64-slice CT scan).

patient; however, 4 patients required coil embolization of the origin of the left subclavian $(\mathrm{n}=3)$ or ligation of the prevertebral segment $(n=1)$ to seal the endoleak. Unless the patient has symptoms indicating a need to revascularize the LSA, we prefer coiling the origin of the left subclavian because it is relatively easy to perform percutaneously via the left brachial artery and well tolerated by the patient, and we have had good success sealing these endoleaks. The incidence of type II endoleaks resulting from patent intercostal arteries was low $(2 / 66,3 \%)$, similar to the rate reported in the literature. ${ }^{16,20,28}$ We managed these patients conservatively because type II endoleaks emanating from patent intercostals are thought to pose a low risk for aortic rupture and eventually seal spontaneously.

\section{CONCLUSIONS}

In the majority of patients requiring endovascular repair for a broad range of thoracic aortic pathologies, coverage of the LSA without previous or concomitant revascularization is well tolerated, provided they have no contraindication 
to unprotected left subclavian overstenting. Because the risk of critical left upper extremity ischemia is negligible, postoperative left subclavian revascularization can be performed electively for the small percentage of patients in whom persistent and intolerable arm claudication or vertebrobasilar insufficiency develops. Although the incidence of stroke and paraplegia is low and comparable in patients receiving thoracic stent grafts, regardless of left subclavian overstenting, a thorough preoperative evaluation to define the cerebrovascular circulation is warranted to define the subgroup of patients at high risk for posterior circulation strokes who may benefit from preprocedural left subclavian revascularization. Retrograde coil embolization of the LSA origin via the ipsilateral brachial artery is a simple and effective method to treat type II endoleaks.

\section{References}

1. Dake MD, Miller DC, Semba CP, Mitchell RS, Walker PJ, Liddell RP. Transluminal placement of endovascular stent-grafts for the treatment of descending thoracic aortic aneurysms. N Engl J Med. 1994;331:1729-34.

2. Riesenman PJ, Farber MA, Mendes RR, Marston WA, Fulton JJ, Keagy BA. Coverage of the left subclavian artery during thoracic endovascular aortic repair. J Vasc Surg. 2007;45:90-4.

3. Caronno R, Piffaretti G, Tozzi M, Lomazzi C, Rivolta N, Castelli P. Intentional coverage of the left subclavian artery during endovascular stent graft repair for thoracic aortic disease. Surg Endosc. 2006;20:915-8.

4. Rehders TC, Petzsch M, Ince H, Kische S, Korber T, Koschyk DH, et al. Intentional occlusion of the left subclavian artery during stent-graft implantation in the thoracic aorta: risk and relevance. J Endovasc Ther. 2004;11:659-66.

5. Gorich J, Asquan Y, Seifarth H, Kramer S, Kapfer X, Orend KH, et al. Initial experience with intentional stent-graft coverage of the subclavian artery during endovascular thoracic aortic repairs. $J$ Endovasc Ther. 2002;9(Suppl 2): II39-43.

6. Criado FJ, Abul-Khoudoud OR, Domer GS, McKendrick C, Zuzga M, Clark NS, et al. Endovascular repair of the thoracic aorta: lessons learned. Ann Thorac Surg. 2005;80:857-63.

7. Song TK, Donayre CE, Walot I, Kopchok GE, Litwinski RA, Lippmann M, et al. Endograft exclusion of acute and chronic descending thoracic aortic dissections. $J$ Vasc Surg. 2006;43:247-58.

8. Hausegger KA, Oberwalder $\mathrm{P}$, Tiesenhausen $\mathrm{K}$, Tauss J, Stanger O, Schedlbauer $\mathrm{P}$, et al. Intentional left subclavian artery occlusion by thoracic aortic stent-grafts without surgical transposition. J Endovasc Ther. 2001;8:472-6.

9. Melissano G, Civilini E, Bertoglio L, Setacci F, Chiesa R. Endovascular treatment of aortic arch aneurysms. Eur J Vasc Endovasc Surg. 2005;29:131-8.

10. Tiesenhausen K, Hausegger KA, Oberwalder P, Mahla E, Tomka M, Allmayer T, et al. Left subclavian artery management in endovascular repair of thoracic aortic aneurysms and aortic dissections. J Card Surg. 2003;18:429-35.

11. Bavaria JE, Appoo JJ, Makaroun MS, Verter J, Yu ZF, Mitchell RS. Endovascular stent grafting versus open surgical repair of descending thoracic aortic aneurysms in low-risk patients: a multicenter comparative trial. J Thorac Cardiovasc Surg 2007; 133:369-77.

12. Peterson BG, Eskandari MK, Gleason TG, Morasch MD. Utility of left subclavian artery revascularization in association with endoluminal repair of acute and chronic thoracic aortic pathology. J Vasc Surg. 2006;43:433-9.

13. Schoder M, Grabenwoger M, Holzenbein T, Cejna M, Ehrlich MP, Rand T, et al. Endovascular repair of the thoracic aorta necessitating anchoring of the stent graft across the arch vessels. J Thorac Cardiovasc Surg. 2006;131:380-7.

14. Wheatley GH Gurbuz AT III, Rodriguez-Lopez JA, Ramaiah VG, Olsen D, Williams J, et al. Midterm outcome in 158 consecutive Gore TAG thoracic endoprostheses: single center experience. Ann Thorac Surg. 2006;81:1570-7.

15. Chaikof EL, Blankensteijn JD, Harris PL, White GH, Zarins CK, Bernhard VM, et al. Reporting standards for endovascular aortic aneurysm repair. J Vasc Surg. 2002;35:1048-60.

16. Fattori R, Nienaber CA, Rousseau H, Beregi JP, Heijmen R, Grabenwoger M, et al. Results of endovascular repair of the thoracic aorta with the Talent Thoracic stent graft: the Talent Thoracic Retrospective Registry. J Thorac Cardiovasc Surg. 2006;132:332-9.

17. Melissano G, Civilini E, Bertoglio L, Calliari F, Setacci F, Calori G, et al. Results of endografting of the aortic arch in different landing zones. Eur J Vasc Endovasc Surg. 2007;33:561-6; Epub 2007 Jan 3.

18. Makaroun MS, Dillavou ED, Kee ST, Sicard G, Chaikof E, Bavaria J, et al Endovascular treatment of thoracic aortic aneurysms: results of the phase II multicenter trial of the GORE TAG thoracic endoprosthesis. J Vasc Surg. 2005; 41:1-9.

19. Khoynezhad A, Donayre CE, Bui H, Kopchok GE, Walot I, White RA. Risk factors of neurologic deficit after thoracic aortic endografting. Ann Thorac Surg. 2007;83:S882-9.

20. Bortone AS, De Cillis E, D'Agostino D, Luca Tupputi SL. Endovascular treatment of thoracic aortic disease: four years of experience. Circulation. 2004; 110(11 Suppl. 1):II262-7.

21. Appoo JJ, Moser WG, Fairman RM, Cornelius KF, Pochettino A, Woo EY, et al. Thoracic aortic stent grafting: improving results with newer generation investigational devices. J Thorac Cardiovasc Surg. 2006;131:1087-94.

22. Stone DH, Brewster DC, Kwolek CJ, Lamuraglia GM, Conrad MF, Chung TK, et al. Stent-graft versus open-surgical repair of the thoracic aorta: mid-term results. J Vasc Surg. 2006;44:1188-97.

23. Chiesa R, Melissano G, Marrocco-Trischitta MM, Civilini E, Setacci F. Spinal cord ischemia after elective stent-graft repair of the thoracic aorta. J Vasc Surg. 2005;42:11-7.

24. Dake MD, Miller DC, Mitchell RS, Semba CP, Moore KA, Sakai T. The "first generation" of endovascular stent-grafts for patients with aneurysms of the descending thoracic aorta. J Thorac Cardiovasc Surg. 1998;116:689-703.

25. Gravereaux EC, Faries PL, Burks JA, Latessa V, Spielvogel D, Hollier LH, et al Risk of spinal cord ischemia after endograft repair of thoracic aortic aneurysms. J Vasc Surg. 2001;34:997-1003.

26. Parmer SS, Carpenter JP, Stavropoulos SW, Fairman RM, Pochettino A, Woo EY, et al. Endoleaks after endovascular repair of thoracic aortic aneurysms. $J$ Vasc Surg. 2006;44:447-52.

27. Czerny M, Grimm M, Zimpfer D, Rodler S, Gottardi R, Hutschala D, et al. Results after endovascular stent graft placement in atherosclerotic aneurysms involving the descending aorta. Ann Thorac Surg. 2007;83:450-5.

28. Hansen CJ, Bui H, Donayre CE, Aziz I, Kim B, Kopchok G, et al. Complications of endovascular repair of high-risk and emergent descending thoracic aortic aneurysms and dissections. J Vasc Surg. 2004;40:228-34. 